\title{
LITERASI KEUANGAN DOSEN-DOSEN PERGURUAN TINGGI DI PALEMBANG: FAKTOR GENDER DAN USIA
}

\author{
${ }^{1}$ Anastasia Sri Mendari, ${ }^{2}$ Fransiska Soejono \\ Fakultas Bisnis dan Akuntansi Universitas Katolik Musi Charitas \\ 1anastasia@ukmc.ac.id, 2fransiska@ukmc.ac.id
}

\begin{abstract}
This study aims to measure the level of financial literacy of lecturers in Palembang. The method of analysis in this research is descriptive analysis. The number of respondents in this study were 153 respondents. Data collection techniques used survey techniques with questionnaires. Financial literacy index is determined through four stages: (1) Grouping of financial literacy variables in 2 groups, namely basic financial literacy and advanced financial literacy, (2) giving score 1 for correct answer and 0 for other answer that is unknow, wrong answer and refused to answer, (3) Calculate the weight of each variable by using simple weight, (4) Calculate index of financial literacy. The results showed that on average the basic financial literacy of lecturers in Palembang was included in the moderate category, while the average advanced financial literacy was in the low category. The level of financial literacy or Financial Literacy Index as a whole including the low category. Distribution of basic financial literacy based on gender and age average dominant in high category reverse dominant advanced financial literacy distribution in low category.
\end{abstract}

Keyword: Literacy Index, basic financial literacy, advanced financial literacy

\begin{abstract}
Abstrak. Penelitian ini bertujuan mengukur tingkat literasi keuangan dosen-dosen di Palembang. Metode analisis dalam penelitian ini adalah analisis deskriptif. Jumlah responden dalam penelitian ini sebanyak 153 responden. Teknik pengumpulan data menggunakan teknik survei dengan kuesioner. Indeks literasi keuangan ditentukan melalui empat tahapan yaitu (1) Mengelompokkan variabel literasi keuangan dalam 2 kelompok yaitu basic financial literacy dan advanced financial literacy, (2) Memberikan skor 1 untuk jawaban yang benar dan 0 untuk jawaban lainnya yaitu tidak tahu, salah dan menolak untuk menjawab, (3) Menghitung bobot tiap variabel dengan menggunakan simple weight, (4) Menghitung indeks literasi keuangan. Hasil penelitian menunjukkan bahwa secara rata-rata basic financial literacy dosen-dosen di Palembang termasuk dalam kategori moderat, sedangkan rata-rata advanced financial literacy termasuk kategori rendah. Adapun tingkat literasi keuangan atau Financial Literacy Index secara keseluruhan termasuk kategori rendah. Distribusi Basic financial literacy berdasarkan gender dan usia rata-rata dominan di kategori tinggi sebaliknya distribusi advanced financial literacy dominan pada kategori rendah.
\end{abstract}

\section{PENDAHULUAN}

Perkembangan dunia keuangan dewasa ini memberikan banyak pilihan kepada masyarakat didalam membuat keputusan-keputusan keuangan, berbagai produk-produk keuangan baru semakin variatif dan menuntut orang-orang untuk memahaminya apabila mau memanfaatkannya, literasi keuangan semakin menjadi hal yang signifikan diperlukan karena dalam literasi keuangan tersedia berbagai macam cara serta pengetahuan untuk menjadikan seseorang cerdas dalam mengelola keuangannya. Menurut Muliaman D. Hadad kurangnya literasi keuangan membawa dampak pada consumer behaviour yang buruk, hal ini membawa 
konsumen pada paparan kejahatan keuangan seperti investasi bodong (Aprillia, 2017).

Literasi keuangan dapat diartikan sebagai suatu rangkaian proses atau kegiatan untuk meningkatkan pengetahuan (knowledge), keterampilan (skill) dan keyakinan (confidendence) konsumen maupunmasyarakat agar mereka mampu mengelola keuangan pribadi dengan lebih baik, dengan definisi seperti ini, masyarakat diberikan bekal edukasi yang memadai dan mencukupi untuk mengambil keputusan keuangan dengan lebih baik, sesuai dengan apa yang mereka butuhkan dan memberikan manfaat yang lebih besar. Secara umum literasi keuangan dipakai sebagai alat ukur untuk mengetahui seberapa banyak masyarakat yang tidak memiliki pengetahuan mengenai lembaga jasa keuangan beserta produk dan jasa keuangan yang tersedia. Masyarakat bisa memilih produk dan jasa keuangan yang sesuai dengan kebutuhan mereka, mengetahui dengan benar manfaat dan risikonya, serta hak dan kewajiban sebagai konsumen keuangan (Sugiarto, 2013).

Kualitas literasi keuangan masyarakat memiliki peran strategis, banyaknya kasus investasi bodong di masyarakat, karena ketidaktahuan masyarakat tentang jasa keuangan mana yang resmi dan tidak. Oleh karena itu, literasi keuangan menjadi program Otoritas Jasa Keuangan (OJK) dalam perlindungan konsumen. Sesuai dengan amanat Undang-Undang Otoritas Jasa Keuangan Nomor 21 Tahun 2011 tentang Otoritas Jasa Keuangan, salah satu tujuan dibentuknya Otoritas Jasa Keuangan (OJK) adalah untuk melindungi kepentingan konsumen dan masyarakat. Sebagai implementasi dari tujuan tersebut, OJK berkewajiban untuk memberikan informasi dan edukasi kepada masyarakat atas karakteristik sektor jasa keuangan, layanan, dan produknya.

Literasi keuangan merupakan salah satu fokus kebijakan pemerintah dan lembaga keuangan dalam dekade terakhir ini. Pada tanggal 19 November 2013, Otoritas Jasa Keuangan (OJK) dan Asosiasi Lembaga Jasa Keuangan (LJK) meluncurkan program Strategi Nasional Literasi Keuangan. Misi dari strategi nasional literasi keuangan adalah melakukan edukasi di bidang keuangan kepada masyarakat Indonesia agar dapat mengelola keuangan secara cerdas. Pelaksanaan Edukasi dalam rangka meningkatkan keuangan masyarakat sangat diperlukan berdasarkan survei nasional yang dilakukan oleh OJK. Hasil survei yang dilakukan OJK pada tahun 2013 menunjukkan bahwa tingkat literasi keuangan masyarakat Indonesia masih relatif rendah, indeks literasi keuangan sebesar $21,84 \%$. Hasil survei menjadi masukan dalam Strategi Nasional Literasi Keuangan Indonesia yang di dalamnya juga terdapat aspek inklusi keuangan, yang menjadi pedoman bagi OJK danindustrijasakeuangan dalammelaksanakan kegiatan sebagai upaya peningkatan literasi dan inklusi keuangan masyarakat Indonesia. Upaya yang dilakukan dalam meningkatkan literasi keuangan salah satunya adalah dengan edukasi pada masyarakat.

Jika pada tahun 2013 OJK melakukan survei nasional terhadap 8.000 responden yang tersebar di 40 wilayah pada 20 provinsi, maka tahun 2016 OJK kembali melakukan survei terhadap 9680 responden yang berada di 34 propinsi dan 64 kota /kabupaten. Hasil survei tahun 2016, menunjukkan adanya peningkatan tingkat literasi keuangan dari 21,84\% menjadi 29,66\% (OJK: Hasil Survei Literasi Keuangan 2016). Harapannya, dengan tingkat literasi keuangan masyarakat yang meningkat dapat membuat keputusan keuangan dengan lebih baik sehingga perencanaan keuangan keluarga atau pribadi menjadi lebih optimal. Peningkatan ini tak lepas dari usaha OJK dalam melakukan edukasi di masyarakat. Tahun 2013 Otoritas Jasa Keuangan menerbitkan buku Seri Litearsi Keuangan Indonesia : Perencanaan Keuangan Ibu Rumah Tangga. Ibu Rumah tangga menjadi sasaran edukasi literasi keuangan, tidak hanya menyasar ibuibu rumah tangga dan UMKM, OJK juga merangkul dunia pendidikan. Kusumaningtuti (2016), seorang anggota Dewan Komisioner Bidang Edukasi dan Perlindungan Konsumen dalam suatu sambutan menyatakan bahwa guna menyikapi globalisasi dalam sistem keuangan serta inovasi finansial yang menciptakan kompleksitas produk dan layanan keuangan, diperlukan generasi yang memiliki pemahaman, keterampilan dan keyakinan dalam menggunakan produk dan layanan jasa keuangan. Hal ini penting karena bukti empiris menunjukkan bahwa hal tersebut merupakan salah satu kunci pertumbuhan ekonomi dan 
stabilitas sistem keuangan. Oleh karena itu, Otoritas Jasa Keuangan (OJK) meletakkan program peningkatan literasi keuangan dan perluasan akses masyarakat terhadap industri keuangan formal sebagai salah satu program prioritas. OJK telah menerbitkan Strategi Nasional Literasi Keuangan Indonesia (SNLKI) agar upaya peningkatan literasi dan inklusi keuangan berlangsung dengan lebih terstruktur dan sistematis. Salah satu pilar dalam SNLKI tersebut adalah penyusunan dan penyediaan materiliterasikeuangan padasetiap jenjang pendidikan formal. OJK bersamasama dengan Kementerian Pendidikan dan Kebudayaan dan Industri Jasa Keuangan telah menyusun buku literasi keuangan "Mengenal JasaKeuangan" untuk tingkat SD (kelas IV dan V), serta buku "Mengenal Otoritas Jasa Keuangandan Industri Jasa Keuangan" untuk tingkat SMP dan tingkat SMA (kelas X). Bekerja sama dengan Kementerian Riset, Teknologi dan Pendidikan Tinggi, OJK juga berusaha mendekatkan mahasiswa dengan industri jasa keuangan melalui buku literasi keuangan untuk Perguruan Tinggi.

Edukasi Literasi keuangan melalui dunia pendidikan tidak lepas dari peran serta guruguru dan dosen. Guru dan dosen menjadi ujung tombak didalam memberikan edukasi kepada peserta didik (siswa dan mahasiswa), harapannya semakin dini masyarakat diperkenalkan dengan literasi keuangan.Upaya OJK meningkatkan literasi keuangan di dunia pendidikan didukung pula oleh Peraturan Menteri Pendidikan dan Kebudayaan Nomor 24/2016 tentang Kompetensi Inti dan Kompetensi Dasar Pelajaran pada Kurikulum 2013 pada Pendidikan Dasar dan Pendidikan Menengah. Aturan itu menetapkan pemahaman mengenai lembaga jasa keuangan dan OJK sebagai cakupan kompetensi dasar tingkat SMA (Edukasi Konsumen Maret 2017). Selain membangun kerjasama dengan Menteri Pendidikan dan Kebudayaan, OJK juga membangun kerja sama dengan Kementerian Riset, Teknologi, dan Pendidikan Tinggi, bersama dengan berbagai universitas dan juga industri jasa keuangan dalam menyusun materi edukasi keuangan melalui perguruan tinggi. Otoritas Jasa Keuangan (OJK) meluncurkan buku Seri Literasi Keuangan tingkat Perguruan Tinggi sebagai bentuk implementasi dari Strategi
Nasional. Literasi Keuangan Indonesia (SNLKI). Penyusunan buku berpedoman pada ketentuan dan teori yang berlaku di masing-masing sektor jasa keuangan, standar penyampaian materi pada buku-buku modul kuliah yang ada saat ini, serta disesuaikan dengan aplikasi pemanfaatannya di dunia kerja maupun dalam kehidupan sehari-hari. Untuk mendorong pemanfaatannya OJK berkoordinasi dengan Kementerian Riset Teknologi dan Pendidikan Tinggi. Mantan Ketua Dewan Komisioner OJK Muliaman D. Hadad mengatakan upaya yang ditempuh oleh OJK ini guna meningkatkan literasi keuangan masyarakat (http://finansial.bisnis.com).

Pentingnya peningkatan literasi keuangan masyarakat melalui perguruan tinggi tidak terlepas dari peran dosen. Dosen juga diharapkan memiliki tingkat literasi keuangan yang juga cukup baik. Selama ini belum banyak penelitian mengenai tingkat literasi keuangan pada dosen-dosen perguruan tinggi. Penelitian ini bertujuan untuk mengukur tingkat literasi keuangan dosen-dosen perguruan tinggi. Adapun dalam penelitian ini mengacu pada penelitian pilot project "Developing an Indonesian Financial Literacy Index" yang merupakan kerja sama antara DEFINIT SEADI (Support for Economic Analysis Develpoment in Indonesia), dan Otoritas Jasa Keuangan (OJK) yang mengembangkan metodologi untuk mengukur tingkat literasi keuangan rumah tangga di Indonesia.

\section{TINJAUAN PUSTAKA}

\section{Definisi Literasi Keuangan}

Definisi Literasi keuangan dirumuskan oleh berbagai pihak cukup beragam. Beberapa diantaranya adalah: The Presidents Advisory Council on Financial Literacy (PACFL dalam Hunge at.al, 2009), mendefinisikan Financial literacy: the ability to use knowledge and skills to manage financial resources effectively for a life time of financial well-being (Kemampuan menggunakan pengetahuan dan ketrampilan secara efektif untuk mengelola sumber daya keuangan untuk mencapai kesejahteraan). Kim (dalam Houston, 2010) merumuskan financial literacy is a basic knowledge that people need in order to survive in a modern society (pengetahuan dasar yang dibutuhkan orang agar dapat bertahan dalam masyarakat 
modern). ANZ (Survey ANZ 2015) telah melakukan survey literasi keuangan sejak tahun 2002, mendefinisikan financial Literacy sebagai: the ability to make informed judgements and to take effective decisions regarding the use and management of money (kemampuan untuk membuat penilaian yang tepat dan mengambil keputusan yang efektif sehubungan dengan penggunaan dan pengelolaan uang). Literasi keuangan dapat diartikan sebagai kemampuan untuk mengevaluasi dan mengelola secara efektif keuangan dalam mencapai keuangan yang baik (American Institute of Certified Public Accountants tahun 2013, dalam Indrawati tahun 2015).

\section{Manfaat Literasi Keuangan}

Manfaat literasi keuangan bagi masyarakat antara lain, masyarakat menjadi mampu memilih dan memanfaatkan produk dan layanan jasa keuangan yang sesuai kebutuhan; memiliki kemampuan dalam melakukan perencanaan keuangan dengan lebih baik juga dapat terhindar dari aktivitas investasi pada instrumen keuangan yang tidak jelas. Literasi keuangan juga memberikan manfaat yang besar bagi sektor jasa keuangan. Lembaga keuangan dan masyarakat saling membutuhkan satu sama lain sehingga semakin tinggi tingkat literasi keuangan masyarakat, maka semakin banyak masyarakat yang akan memanfaatkan produk dan layanan jasa keuangan (OJK).

Penelitian Chen dan Volpe (1998) menemukan bahwa dengan memiliki literasi finansial, mahasiswa mampu membuat keputusan untuk kehidupan mereka dan bertanggung jawab atas tindakan mereka sendiri. Jadi literasi keuangan bermanfaat bagi mahasiswa di dalam membuat kepuusan keuangan yang efektif.

Literasi keuangan dibutuhkan di dalam menyusun perencanaan keuangan, Byrne tahun 2007 dalam Rita dan Santoso (2015) menemukan bahwa pengetahuan keuangan yang rendah akan menyebabkan pembuatan rencana keuangan yang salah, dan menyebabkan bias dalam pencapaian kesejahteraan di saat usia tidak produktif lagi. Literasi keuangan juga merupakan faktor yang fundamental untuk pertumbuhan ekonomi dan stabilitas keuangan (Financial
Literacy Assessment Framework (OECD INFE, 2012). Sedangkan di dalam literatur bisnis dan kewirausahaan disebutkan bahwa kurangnya pengetahuan dan akses terhadap sumber daya keuangan telah dihubungkan dengan ketidakmampuan perusahaan dalam mencapai tujuan (Beck, DemirgucKunt, dan Maksimovic, 2005; Hutchinson dan Xavier, 2006; Malo dan Norus, 2009; serta Coad dan Tamvada, 2012, dalam Aribawa 2016). Literatur yang lain juga menegaskan bahwa literasi dan inklusi keuangan akan mampu meningkatkan pertumbuhan perusahaan (Cooper, Gimeno-Gascon, dan Woo, 1994; Storey, 1994; Forbes Insights, 2011 dalam Aribawa 2016).

Peningkatan literasi keuangan memiliki dampak positif pada kehidupan pribadi dan bisnis masyarakat. Pengetahuan keuangan membantu mengurangi tekanan sosial dan psikologis dan meningkatkan kesejahteraan keluarga dalam kehidupan pribadi. Pengetahuan keuangan mengurangi stres, penyakit, perselisihan keuangan, pelecehan anak dan konflik di antara keluarga, selain itu literasi keuangan yang tinggi menurunkan stres emosional dan kecemasan di tempat kerja, keuntungan terbesar dari pendidikan literasi keuangan adalah mengurangi masalah keuangan karyawan dan mendorong mereka untuk bertanggung jawab atas pembiayaan mereka sendiri dan keduanya akan membantu meningkatkan efisiensi organisasi (Fox et al. 2005, Kim 2007,Vitt et al.2000 dalam Taft et al. 2013).

Penelitian-penelitian literasi keuangan cukup banyak dilakukan baik di luar negeri maupun di dalam negeri. Hasil kajian tentang literasi keuangan bermanfaat bagi masyarakat, mengingat pentingnya literasi keuangan bagi individu. Chen dan Volpe (1998) mengukur literasi keuangan menggunakan pertanyaan dari empat concept meliputi: Basic concepts, Borrowing concepts, Saving/Investing concepts, dan Protection concepts, diuraikan dalam 36 pertanyaan. Jumlah responden sebanyak 924 orang mahasiswa dari 14 universitas di California, Florida, Kentucky, Massachussetts, Ohio, dan Pennsylvania. Penelitian bertujuan untuk melihat gambaran personal financial literacy di kalangan mahasiswa, menganalisa hubungan karakteristik mahasiswa dengan financial 
literacy, serta menganalisa dampak dari pengetahuan terhadap opini dan keputusan mahasiswa terhadap isu-isu keuangan. Metode yang digunakan adalah analisis deskriptif, regresi logistik dan ANOVA. Temuan dalam penelitian ini menunjukkan mahasiswa dari program studi non-bisnis, perempuan, junior, usia dibawah 30 tahun, dan pengalaman kerja sedikit diasosiasikan dengan tingkat personal financial literacy yang rendah, dan cenderung memiliki opini dan keputusan keuangan yang salah.

Beal dan Delpachitra (2003) melakukan survei terhadap 837 mahasiswa di University of Southern Quensland, Australia untuk mengukur tingkat financial literacy dengan menggunakan 25 pertanyaan pilihan berganda terkait keuangan. Variabel dependennya adalah financial literacy dan variabel independennya adalah program studi, jenis kelamin, usia, status kekeluargaan, jenjang pendidikan, jenis pekerjaann, pengalamana kerja, pendapatan, toleransi terhadap risiko. Metode yang digunakan adalah analisis deskriptif dan regresi logistik. Hasil penelitian menunjukkan responden memiliki financial literacy yang rendah.

Penelitian sejenis juga dilalukan oleh Ibrahim et.al, (2009) dengan judul "A Study on Financial Literacy of Malaysian Degree Students", survey dilakukan terhadap 200 mahasiswa Universitas Teknologi MARA Kedah, metode penelitian adalah analisis deskriptif, T-test,ANOVA, Pearson's Correlation dan Chi-Square. Hasil penelitian menunjukkan tingkat pengetahuan keuangan dan kemampuan manajemen keuangan yang sangat lemah.

Keown (2011) melakukan penelitian berjudul "The Financial Knowledge of Canadians". Penelitian dilakukan terhadap 15.519 orang pada 10 propinsi di Kanada untuk mengetahui gambaran pengetahuan keuangan masyarakat Kanada. Variabel dependennya adalah financial knowledge dan variabel independen (eksplanatori) adalah usia, jenis kelamin, status keluarga, status imigrasi, tingkat pendidikan, status pekerjaan, status kepemilikan rumah, dan wilayah domisili. Penelitian menggunakan 14 pertanyaan terkait pengetahuan mengenai manajemen uang harian, penganggaran dan perencanaan keuangan jangka panjang dan dianalisis menggunakan metode analisis deskriptif. Hasil penelitian menunjukkan rata-rata jawaban yang benar dari seluruh responden adalah $67 \%$.

Penelitian literasi keuangan diantaranya dilakukan oleh Krisna et.al (2010) yang meneliti literasi keuangan pada mahasiswa Universitas Pendidikan Indonesia (UPI) Bandung, skor rata-rata literasi keuangan sebesar $63 \%$, yang mengarah pada kategori rendah. Penelitian yang dilakukan Nidar dan Bestari (2012) pada mahasiswa Universitas Pajajaran menunjukkan rata -rata skor literasi keuangan mahasiswa Pajajaran 42,1\% dan termasuk kategori rendah, konten pertanyaan dalam penelitian ini meliputi empat konsep (Houston, 2010) yakni : mengukur literasi keuangan menggunakan pertanyaan dari empat concept meliputi: Basic concepts, Borrowing concepts, Saving/Investing concepts, dan Protection concepts.

Mendari dan Kewal (2013) meneliti literasi keuangan pada mahasiswa STIE Musi Palembang, hasil penelitiannya menunjukkan skor rata-rata literasi keuangan Mahasiswa STIE Musi 37,07\%, hal ini mengindikasikan literasi keuangan yang rendah. Penelitian ini juga menggunakan daftar pertanyaan yang mencakup empat konsep mengukur literasi keuangan menggunakan pertanyaan dari empat konsep meliputi: Basic concepts, Borrowing concepts, Saving/Investing concepts, dan Protection concepts. Nababan dan Sadalia (2013) dalam penelitiannya terhadap mahasiswa S1 Fakultas Ekonomi Universitas Sumatera Utara, menyimpulkan rata-rata skor $56,11 \%$ dan termasuk kategori rendah.

Penelitian yang dilakukan oleh Sina dan Nggili (2013) pada dosen-dosen muda Universitas Kristen Satyawacana Salatiga menunjukkan bahwa literasi keuangan dosen-dosen muda UKSW berada pada tingkatan rendah. Penelitian Indrawati (2015) menggunakan deskriptif kuantitatif, tingkat literasi keuangan masyarakat perkotaan di Kabupaten Jember tergolong rendah untuk basic financial literacy 38,37 dan untuk advanced financial literacy 21,89. Aribawa (2016) meneliti pengaruh literasi keuangan terhadap kinerja dan keberlangsungan UMKM 
di Jawa Tengah, penelitian ini menunjukkan tingkat literasi keuangan tergolong moderat (67\%).

Margaretha dan Prambudhi (2015) meneliti literasi keuangan pada mahasiswa S1 Fakultas Ekonomi Universitas Trisakti. Penelitian ini menggunakan kuesioner yang disebarkan sebanyak 625 kuesioner dan hanya 584 kuesioner yang dapat digunakan. Metode analisis data adalah statistik deskriptif dan uji ANOVA, daftar pertanyaan dalam penelitian ini jika dilihat dari konten pertanyaan menurut Houston (2010) menggunakan pertanyaan dari empat concept meliputi: Basic concepts, Borrowing concepts, Saving/Investing concepts, dan Protection concepts, temuan dalam penelitian ini tingkat literasi keuangan mahasiswa adalah 48,91\% berada dalam kategori rendah.

Survei yang dilakukan oleh DEFINIT, USAID, dan OJK (2013), ditujukan pada rumah tangga di tiga kota besar di Indonesia yakni Medan, Jakarta dan Surabaya, jumlah responden 450 orang, temuan dari survei tersebut untuk basic financial literacy hasilnya cukup beragam diantara responden, menurut tingkat pendidikan, tingkat pendapatan, dan gender, basic financial literacy index bardasarkan simple weight adalah 62,60, sedangkan berdasarkan the factor analysis method adalah 66,5. Sedangkan rata-rata advanced financial literacy index hasilnya sangat rendah, rata-rata advanced financial literacy index berdasarkan simple weight adalah 16,24, sedangkan berdasarkan factor analysis method adalah 18,47. Secara keseluruhan, Financal Literacy Index (tingkat literasi ) berdasarkan simple wight adalah 39,42 dan berdasarkan factor analysis method adalah 42,51, berarti tingkat literasi keuangan responden tergolong rendah. Secara keseluruhan responden dengan tingkat pendidikan dan tingkat pendapatan yang tinggi memiliki basic financial literacy yang lebih tinggi, dan responden laki-laki memiliki basic financial literacy yang lebih tinggi dibandingkan yang wanita. Hasil survei juga menunjukkan hubungan antara rendahnya kepemilikan aset finansial yang kompleks seperti saham, obligasi, dan reksadana dengan rendahnya advanced financial literacy.

Survei nasional literasi keuangan yang dilakukan OJK tahun 2013 terhadap
8.000 responden yang tersebar di 40 wilayah pada 20 provinsi (www.ojk.go.id), menunjukkan tingkat literasi keuangan penduduk Indonesia yang dibagi dalam empat bagian, yakni:

1. Well literate $(21,84 \%)$, yakni memiliki pengetahuan dan keyakinan tentang lembaga jasa keuangan serta produk jasa keuangan, termasuk fitur, manfaat dan risiko, hak dan kewajiban terkait produk dan jasa keuangan, serta memiliki keterampilan dalam menggunakan produk dan jasa keuangan.

2. Sufficient literate $(75,69 \%)$, memiliki pengetahuan dan keyakinan tentang lembaga jasa keuangan serta produk dan jasa keuangan, termasuk fitur, manfaat dan risiko, hak dan kewajiban terkait produk dan jasa keuangan.

3. Less literate $(2,06 \%)$, hanya memiliki pengetahuan tentang lembaga jasa keuangan, produk dan jasa keuangan.

4. Not literate $(0,41 \%)$, tidak memiliki pengetahuan dan keyakinan terhadap lembaga jasa keuangan serta produk dan jasa keuangan, serta tidak memiliki keterampilan dalam menggunakan produk dan jasa keuangan.

Pada tahun 2016 OJK kembali melakukan survei, kali ini dilakukan terhadap 9680 responden, di 34 propinsi dan 64 kota / kabupaten. Hasil survei 2016, menunjukkan adanya peningkatan tingkat literasi keuangan dari 21,84\% menjadi 29,66\% (OJK: Hasil Survei Literasi Keuangan 2016).

\section{METODE PENELITIAN}

Penelitian ini merupakan penelitian dasar yaitu penelitian yang menghasilkan pokok pengetahuan untuk meningkatkan pemahaman pada masalah tertentu yang kerap terjadi dalam konteks organisasi dan mencari metode untuk memecahkannya (Sekaran, 2009). Penelitian ini merupakan penelitian deskriptif kualitatif yaitu penelitian yang bermaksud menggambarkan/ mendeskripsikan kondisi tingkat literasi keuangan di kalangan pendidik (guru dan dosen) saat ini. Populasi penelitian adalah seluruh guru dan dosen di Palembang. 
Teknik sampling yang digunakan adalah teknik sampling snow ball. Jumlah yang diambil

minimal sebanyak 5 kali jumlah pertanyaan (Wiyono, 2011).

Tabel 1

Variabel Basic financial literacy

\begin{tabular}{|c|c|}
\hline \multicolumn{2}{|r|}{ Pertanyaan } \\
\hline $\begin{array}{l}\text { Kartu identitas } \quad(\mathrm{KTP} / \\
\text { SIM) }\end{array}$ & $\begin{array}{l}\text { apakah Anda membutuhkan kartu identitas ( seperti KTP atau SIM) saat } \\
\text { membuka rekening tabungan di bank }\end{array}$ \\
\hline $\begin{array}{l}\text { Jumlah minimum untuk } \\
\text { membuka rekening } \\
\text { tabungan }\end{array}$ & $\begin{array}{l}\text { apakah Anda harus menyetor sejumlah uang tertentu sebagai setoran awal untuk } \\
\text { membuka rekening tabungan di bank }\end{array}$ \\
\hline Saldo minimum tabungan & Apakah umumnya rekening tabungan memiliki saldo minimum ? \\
\hline $\begin{array}{l}\text { Jaminan simpanan dari } \\
\text { pemerintah }\end{array}$ & $\begin{array}{l}\text { apakah simpanan nasabah dijamin pemerintah sesuai ketentuan yang berlaku, } \\
\text { jika bank mengalami kebangkrutan }\end{array}$ \\
\hline Simple interest & $\begin{array}{l}\text { Jika anda menabung sebesar Rp } 1.000 .000 \text { dengan bunga } 4 \% \text { pertahun ( anggap } \\
\text { saja tidak ada biaya administrasi dan tabungan anda tidak pernah ditarik), setelah } \\
1 \text { tahun, berapa besar uang tabungan anda? }\end{array}$ \\
\hline Compounded interest & $\begin{array}{l}\text { Jika anda menabung sebesar Rp } 1.000 .000 \text { dengan bunga } 4 \% \text { pertahun ( anggap } \\
\text { saja tidak ada biaya administrasi dan tabungan anda tidak pernah ditarik), setelah } \\
2 \text { tahun, berapa besar uang tabungan anda? }\end{array}$ \\
\hline $\begin{array}{l}\text { Loan (perhitungan tingkat } \\
\text { bunga kredit) }\end{array}$ & $\begin{array}{l}\text { Anggap saja Anda mengambil kredit bank sebesar Rp } 1.000 .000 \text { untuk dibayarkan } \\
\text { kembali selama setahun. Biaya kreditnya Rp 50.000. Berapakah tingkat bunga } \\
\text { kredit anda? }\end{array}$ \\
\hline Discount & $\begin{array}{l}\text { Jika anda ingin membeli televisi dengan merk dan model yang sama pada } 2 \text { toko } \\
\text { yang berbeda, dengan harga Rp. } 2.000 .000 \text {, toko A memberi diskon Rp } 250.00 \text {, } \\
\text { sedangkan toko B memberi diskon } 10 \% \text {. Toko mana yang memberi tawaran } \\
\text { yang lebih menarik }\end{array}$ \\
\hline Inflasi & $\begin{array}{l}\text { Misalkan bunga tabungan } 1 \% \text { pertahun, dan tingkat inflasi } 2 \% \text { pertahun, } \\
\text { setelah satu tahun kemudian, berapa banyak barang dan jasa yang dapat anda } \\
\text { beli dengan uang tabungan anda }\end{array}$ \\
\hline Time value of money & $\begin{array}{l}\text { Misalkan anda mendapat hadiah uang Rp } 10.000 .000 \text { sekarang, dan } 3 \text { tahun } \\
\text { yang akan datang adik anda juga mendapat uang Rp } 10.000 .000 \text {. Siapa yang } \\
\text { lebih untung dari segi waktu? }\end{array}$ \\
\hline Money illusion & $\begin{array}{l}\text { Misalkan penghasilan anda di tahun } 2017 \text { menjadi } 2 \text { kali lipat dari tahun } 2016 \text {, } \\
\text { dan harga-harga barang juga naik dua kali lipat, berapa banyak barang dan jasa } \\
\text { yang dapat anda beli dengan pendapatan yang diterima di tahun } 2017\end{array}$ \\
\hline \multicolumn{2}{|r|}{ Sumber: Rooij, Lusardi and Alessie (2007) } \\
\hline \multicolumn{2}{|r|}{$\begin{array}{c}\text { Tabel } 2 \\
\text { Variabel } \text { Advanced financial literacy }\end{array}$} \\
\hline \multicolumn{2}{|r|}{ Pertanyaan } \\
\hline Fungsi Pasar Modal & $\begin{array}{l}\text { pernyataan berikut mana yang menggambarkan fungsi utama pasar } \\
\text { saham }\end{array}$ \\
\hline $\begin{array}{l}\text { Interest rate and bond price } \\
\text { (tingkat bunga dan harga obligasi) }\end{array}$ & $\begin{array}{l}\text { Jika suku bunga cenderung turun, apa yang terjadi dengan harga } \\
\text { obligasi? }\end{array}$ \\
\hline $\begin{array}{l}\text { Returns on stock versus bond } \\
\text { (Pendapatan saham vs obligasi) }\end{array}$ & $\begin{array}{l}\text { Membeli saham perusahaan biasanya memberikan pendapatan yang } \\
\text { lebih aman dari pada membeli reksadana / obligasi }\end{array}$ \\
\hline
\end{tabular}




\section{Pertanyaan}

Risk of bond and stock

(Risiko saham dan obligasi)

The meaning of buying stock (pengertian membeli saham)

The meaning of buying bond (pengertian membeli obligasi)

Penalty when selling bond before maturity

(Pinalti menjual obligasi sebelum jatuh tempo)

Which investment give the highest return

(Pilihan investasi dengan keuntungan tinggi))

Which investment produce the highest return fluctuation

(Pilihan investasi dengan fluktuasi penghasilan paling tinggi / risiko tinggi))

To put or not to put your investments into one basket (diversifikasi investasi)
Menurut pendapat anda normalnya apakah obligasi lebih berisiko dari saham ?

Mana dari pernyataan berikut ini yang benar? Jika seseorang membeli saham perusahaan B di pasar modal, maka berarti .....

Mana dari pernyataan berikut ini yang benar?Jika seseorang membeli Obligasi perusahaan B maka berarti .....

Jika anda membeli obligasi dengan jatuh tempo 10 tahun, itu berarti setelah lima tahun anda tidak dapat menjualnya tanpa kena pinalti yang besar

mengingat jangka waktu yang panjang, normalnya yang akan memberi keuntungan yang paling besar adalah:

Normalnya, aset mana yang paling tinggi fluktuasi penghasilannya dari waktu ke watu

Ketika seorang investor menempatkan uangnya pada berbagai jenis harta ( aset), maka resiko kehilangan uang ( kerugian) menjadi :

Sumber: Rooij, Lusardi and Alessie (2007)

Penelitian ini mengadopsi daftar pertanyaan yang disusun oleh DEFINIT, yang lebih mengacu pada penelitian Van Rooij, Lusardi and Alessie (2007), didalam penelitian ini daftar pertanyaan juga diklasifikasikan menjadi dua kelompok yaitu Basic Literacy dan Advanced Literacy dalam penelitian ini daftar pertanyaan untuk mengukur tingkat literasi keuangan mencakup dua konsep yaitu Basic concepts dan Saving/Investing concepts.

Tahapan/proses analisis data
mengikuti Definit (2013) meliputi pertama, mengelompokkan variabel ke dalam dua kelompok. Pengelompokan variabel literasi finansial terdiri dari: basic dan advance. Kelompok basic terdiri dari 11 variabel, sedangkan advance terdiri dari 10 variabel. Kedua, menetapkan skor penilaian pada setiap variabel. Pada setiap variabel baik pada tabel 1 maupun tabel 2, dilakukan penilaian yaitu jawaban benar diberi nilai 1 dan jawaban lainnya (salah, tidak tahu dan tidak ada jawaban) diberi nilai 0. Ketiga, Menghitung Bobot untuk setiap variabel. Penelitian ini menggunakan satu metode yang sudah diimplementasikan oleh peneliti terdahulu untuk menilai bobot pada setiap variabel literasi financial yaitu metode bobot sederhana (simple weight method) yang digunakan oleh Bumcrot, Lin dan Lusardi (2011) dalam DEFINIT (2013). Pada dasarnya, pendekatan ini memberikan bobot yang sama pada setiap pertanyaan literasi finansial. Index literasi finansial ditentukan berdasarkan jumlah jawaban benar dari setiap responden terhadap pertanyaan-pertanyaan literasi finansial. Responden yang menjawab benar semua akan mendapatkan indeks literasi finansial sebesar jumlah pertanyaan, dan responden yang tidak menjawab benar sama sekali diberi indeks 0 .

$$
\text { Simple_basic_ } \mathrm{W}_{\mathrm{i}}=1 / \mathrm{N}
$$

\section{Dimana:}

1. Simple_basic_ $\mathrm{W}_{\mathrm{i}}$ adalah bobot variabel I dalam kelompok Basic financial literacy.

2. N adalah jumlah variabel dalam kelompok Basic financial literacy. 


$$
\text { Simple_advanced_ } \mathrm{W}_{\mathrm{j}}=1 / \mathrm{M}
$$

Dimana:

1. Simple_advanced_- $\mathrm{W}_{\mathrm{j}}$ adalah bobot variabel I dalam kelompok Advanced financial literacy.

2. $\mathrm{M}$ adalah jumlah variabel dalam kelompok Advanced financial literacy. Simple Weighted Method juga diterapkan untuk keseluruhan variabel yaitu 1/ $(\mathrm{N}+\mathrm{M})$.

Keempat, menentukan Score. Score dihitung menggunakan metode perhitungan yang digunakan oleh penelitian terdahulu yaitu Bumcrot, Lin dan Lusardi (2011) dalam DEFINIT (2013). Skor yang digunakan baik untuk menghitung Skor variabel BFL atau Skor variabel AFL atau skor keseluruhan variabel (BFL dan AFL) adalah sebesar jumlah jawaban benar. Jika jawaban responden untuk 11 pertanyaan BFL benar semua maka besarnya skor adalah 11 dan jika semua jawaban salah maka skor sebesar 0. Jika jawaban responden untuk 10 pertanyaan AFL benar semua maka besarnya skor adalah 10 dan jika semua jawaban salah maka skor sebesar 0 . Jika jawaban responden untuk 21 pertanyaan BFL dan AFL benar semua maka besarnya skor adalah 21 dan jika semua jawaban salah maka skor sebesar 0. Kelima, menghitung Financial Literacy Index (FLI). Financial Literacy Index (FLI) untuk setiap observasi pada masing-masing kelompok variabel selanjutnya dihitung dengan menjumlahkan skor produk dari setiap variabel dan masingmasing bobot yang sesuai. Skor basic dan advance financial literacy dikalikan dengan 100 untuk memudahkan interpretasi. Oleh karena itu, skor untuk basic dan advance financial literacyindex bervariasi antara 1 dan 100. Rumus untuk menghitung basic dan advance financial literacy berdasarkan pada metode bobot sederhana (simple weight method) sebagai berikut:

Basic financial literacy Index:

FLI_Smpl $l_{i, o b s}=\sum_{i=1}^{N}\left(S_{\text {core }} e_{i, o b s} x \operatorname{Smpl} l_{-} b s c_{-} W_{i} x 100\right)$

Dimana:

FLI_Smpl $l_{i, o b s}=$ basic financial literacy index of respondent obs

Score $_{i, o b s}=$ the score of respondent obs in answering variable $\mathrm{i}$

Smpl_bsc_ $W_{i}=$ the simple weight of variable $\mathrm{i}$

Advanced financial literacy index:

FLI_Smpl ${ }_{j, o b s}=\sum_{j=1}^{N}\left(S_{\text {core }} e_{j, o b s} x \operatorname{Smpl} l_{-} a d v a n c e d \_W_{j} x 100\right)$

Dimana:

FLI_Smpl $\}_{j, o b s}=$ advanced financial literacy index of respondent obs.

Score $_{j, o b s}=$ the score of respondent obs in answering variable $\mathrm{j}$.

Smpl_bsc_ $W_{j}=$ the simple weight of variable $\mathrm{j}$.

Sesudah menghitung basic dan advance financial literacy index pada setiap observasi, selanjutnya menghitung total skor Financial
Literacy Index (FLI) untuk setiap responden yang dibangun dari basic dan advance financial literacy index dari observasi yang 
sesuai. Setiap kelompok variabel diberi bobot yang seimbang. Dengan demikian, total skor dari Financial Literacy Index merupakan rata-rata aritmatika yang sederhana dari basic dan advance financial literacy, dengan rumus sebagai berikut:

\section{Simple Weight Method: FLI_Smpl $l_{i, o b s}=\left(0,5 \mathrm{FLI} \operatorname{Smpl}_{i, o b s}\right)+\left(0,5 \mathrm{FLI} \operatorname{Smpl} l_{j, o b s}\right)$}

Hasil perhitungan ini digunakan untuk menilai FLI keseluruhan responden secara rata-rata. Analisa lebih lanjut dilakukan dengan menggunakan hasil perhitungan FLI dengan simple weighted method. Analisa dilakukan berdasarkan hasil Descriptive Statistic dan crosstabs menggunakan alat bantu SPSS versi 16. Crosstabs dilakukan untuk menjelaskan FLI berdasarkan Gender dan Usia.

Penilaian tingkat literasi keuangan akan dibagi dalam tiga kategori sesuai Definit (2013) yaitu Kategori rendah jika Indeks literasi keuangan kurang atau sama dengan 60 $(0 \leq \mathrm{FLI} \leq 60)$, Kategori moderat jika Indeks literasi keuangan lebih dari 60 dan kurang atau sama dengan $80(60<\mathrm{FLI} \leq 80)$, dan Kategori Tinggi jika Indeks Literasi Keuangan lebih besar dari $80(\mathrm{FLI}>80)$. Analisis data dalam riset ini dilakukan dengan melihat informasi statistik deskriptif berdasarkan FLI basic FLI , advanced, dan keseluruhan financial literacy index.

\section{HASIL DAN PEMBAHASAN}

\section{Data dan Profil Responden}

Penelitian ini melibatkan responden beberapa Perguruan Tinggi di Palembang, diantaranya adalah Universitas Katolik Musi Charitas, Universitas IBA, Universitas Sriwijaya,Universitas Palembang, dan Universitas PGRI, jumlah kuesioner yang dibagikan sebanyak 200 kuesioner dan kembali sebanyak 153 kuesioner (76,5\%) penyebaran kuesioner dengan teknik sampling snow ball. Profil responden dapat dijelaskan berdasarkan gender, usia, tingkat penghasilan, pendidikan, kelompok Perguruan Tinggi Negeri/Swasta, dan Fakultas.

Profil responden berdasarkan gender, responden dalam penelitian ini lebih dominan perempuan $(61,4 \%)$, sedangkan laki-laki $(38,6 \%)$. Responden dalam penelitian ini paling banyak berusia antara 30 sampai 40 tahun $(36,6 \%)$, dan yang paling sedikit adalah yang berusia dibawah 30 tahun $(12,4 \%)$.
Responden dengan usia antara 40 sampai 50 tahun sebanyak $29,4 \%$ dan diatas 50 tahun sebanyak $21,6 \%$.

\section{Pengetahuan responden mengenai produk keuangan Deposit Guarantee Scheme}

Penelitian ini menghasilkan informasi bahwa walaupun jumlah responden yang memiliki simpanan di bank jumlahnya besar, namun tidak semuanya mengetahui bahwa simpanan nasabah di bank di jamin oleh pemerintah (grafik 1).

\section{Pengetahuan responden mengenai adanya jaminan pemerintah atas simpanan nasabah}

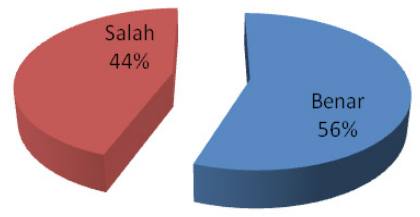

Grafik 1. Pengetahuan Responden Tentang Jaminan Pemerintah akan Simpanan di Bank

Grafik 2 menunjukkan jumlah responden yang menjawab benar mengenai besarnya jumlah jaminan pemerintah atas simpanan nasabah di bank.

\section{Pengetahuan responden mengenai \\ besarnya jumlah simpanan nasabah} yang dijamin pemerintah

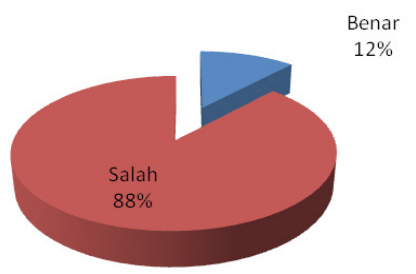

Grafik 2. Pengetahuan Responden Tentang Besarnya Jumlah Jaminan Pemerintah 


\section{Tingkat Literasi Keuangan (Financial Literacy Index)}

Penentuan tingkat literasi keuangan responden dilakukan dengan beberapa tahapan, seperti yang dipaparkan pada bab 4 (metode Penelitian). Penentuan skor dilakukan dengan memberi skor 1 untuk jawaban benar dan 0 untuk jawaban salah, tidak tahu, dan menolak menjawab. Penentuan bobot menggunakan pendekatan metode bobot sederhana (simple weight method) mengacu pada penelitian Bumcrot, Lin dan Lusardi (2011) dalam DEFINIT (2013). Pada dasarnya, pendekatan ini memberikan bobot yang sama pada setiap pertanyaan literasii finansial.

Hasil perhitungan Basic Financial Literacy Index sebesar 68,45, yang berarti literasi keuangan dasar responden tergolong moderat, sedangkan literasi keuangan tingkat lanjutan dapat dilihat dari hasil Advanced Financial Literacy Index sebesar 46,47 yang berarti termasuk rendah. Sedangkan tingkat literasi keuangan atau Financial Literacy Index secara keseluruhan adalah sebesar 57,46, yang dikatagorikan rendah, jadi dapat disimpulkan secara keseluruhan tngkat literasi keuangan responden (Financial Literacy Index) adalah rendah.

Tabel 1. Financial Literacy Index

\begin{tabular}{cccc}
\hline Variabel & Minimum & Maximum & Mean \\
\hline FLI_BFL & 27,27 & 100 & 68,45 \\
FLI_AFL & 0,00 & 100 & 46,47 \\
\hline \multicolumn{4}{c}{ Sumber : data primer diolah }
\end{tabular}

Statistik Deskriptif pada tabel 1 menampilkan statistik deskriptif dengan nilai minimum 27,27 dan nilai maksimum 100, dengan nilai rata-rata 68,45 (untuk Basic Financial Literacy), sedangkan untuk Advanced Financial Literacy nilai terendah 0 dan tertinggi 100, dengan nilai rata-rata 46,47.

Tabel 2 menunjukkan sebesar 39,2\% responden pada Basic Financial Literacy (BFL) tergolong tinggi artinya sebanyak $39,2 \%$ pemahaman responden akan keuangan dasar tergolong tinggi, sedangkan jumlah responden yang Basic Financial Literacy (BFL) rendah dan moderat berimbang sekitar masing-masing 30,1\% dan 30,7\%. Sedangkan sebesar $71,9 \%$ responden tingkat literasi untuk advanced financial tergolong rendah ini berarti pemahaman sebagian besar responden akan investasi jangka panjang seperti saham, obligasi, reksadana dan risiko investasi masih rendah. Sebesar $22,9 \%$ responden pemahaman akan investasi jangka panjang tergolong moderat dan hanya 5,2\% tergolong tinggi.

Tabel 2. Financial Literacy Index Berdasarkan Kelompok

(Basic dan Advanced Financial Literacy)

\begin{tabular}{lcccccc}
\hline \multirow{2}{*}{ Variabel } & \multicolumn{2}{c}{ Low } & \multicolumn{2}{c}{ Moderate } & \multicolumn{2}{c}{ High } \\
\cline { 2 - 7 } & Total & $\mathbf{\%}$ & Total & $\mathbf{\%}$ & Total & $\mathbf{\%}$ \\
\hline FLI_BFL & 46 & 30,1 & 47 & 30,7 & 60 & 39,2 \\
FLI_AFL & 110 & 71,9 & 35 & 22,9 & 8 & 5,2 \\
FLI_All & 78 & 51 & 52 & 34 & 23 & 15 \\
\hline
\end{tabular}

Sumber: data primer yang diolah

\section{Financial Literacy Index Berdasarkan Gender}

Financial Literacy Index berdasarkan gender menampilkan tingkat literasi keuangan dasar atau Basic Financial Literacy (BFL), tingkat literasi keuangan lanjutan atau Advanced Financial Literacy (AFL) dan tingkat literasi keuangan atau Financial Literacy Index (FLI) untuk laki-laki dan perempuan, BFL laki-laki yang tergolong rendah sebesar $19 \%$ sedangkan perempuan sebesar 37\%, menandakan perempuan lebih banyak yang BFL-nya rendah dibandingkan laki-laki. Untuk BFL yang tergolong moderat dan tergolong tinggi jumlah responden lakilaki lebih banyak dibandingkan perempuan. Responden laki-laki yang BFL-nya moderat sebanyak 38,98\% sedangkan perempuan sebesar $25,53 \%$. Untuk yang BFL nya tinggi untuk laki-laki sebesar $42,37 \%$ sedangkan perempuan sebesar 37,23\%. Untuk AFL seimbang jumlahnya antara laki-laki dan perempuan.

Selain BFL dan AFL dapat dilihat juga FLI secara keseluruhan dimana responden laki-laki yang memiliki tingkat literasi keuangan atau Financial literacy index (FLI) tergolong tinggi lebih banyak dibandingkan resonden perempuan, responden laki-laki yang FLI-nya tergolong tinggi sebanyak $15,25 \%$, sedangkan yang perempuan sebanyak $14,89 \%$, demikian juga yang tergolong moderat, yang termasuk moderat untuk lakilaki sebesar $42,37 \%$ dan perempuan sebesar $28,72 \%$, sedangkan FLI-nya tergolong rendah perempuan yang lebih banyak dari laki-laki, jumlah responden perempuan yang tergolong 
rendah FLI nya sebanyak 56\%, dan laki-laki yang FLI-nya rendah sebanyak $42 \%$. Hasil ini mengindikasikan tingkat literasi keuangan laki-laki cenderung lebih baik dibandingkan perempuan, hasil ini juga sejalan dengan survey yang dlakukan DEFINIT (2013) dimana responden laki-laki memiliki basic financial literacy yang lebih tinggi dibandingkan perempuan.

Tabel 3. Financial Literacy Index Berdasarkan Gender

\begin{tabular}{|c|c|c|c|c|c|c|c|c|}
\hline \multirow{2}{*}{ Gender } & \multicolumn{2}{|c|}{ Low } & \multicolumn{2}{|c|}{ Moderate } & \multicolumn{2}{|c|}{ High } & \multicolumn{2}{|c|}{ Total } \\
\hline & Jumlah & $\%$ & Jumlah & $\%$ & Jumlah & $\%$ & Jumlah & $\%$ \\
\hline \multicolumn{9}{|l|}{ FLI_BFL } \\
\hline Laki-laki & 11 & 19 & 23 & 38,98 & 25 & 42,37 & 59 & 100 \\
\hline Perempuan & 35 & 37 & 24 & 25,53 & 35 & 37,23 & 94 & 100 \\
\hline Total & 46 & & 47 & & 60 & & 153 & 100 \\
\hline \multicolumn{9}{|l|}{ FLI_AFL } \\
\hline Laki-laki & 38 & $64 \%$ & 18 & $30,51 \%$ & 3 & 5,08 & 59 & 100 \\
\hline Perempuan & 72 & $77 \%$ & 17 & $18,09 \%$ & 5 & 5,32 & 94 & 100 \\
\hline Total & 110 & & 35 & & 8 & & 153 & $100 \%$ \\
\hline \multicolumn{9}{|l|}{ FLI_All } \\
\hline Laki-laki & 25 & $42 \%$ & 25 & $42,37 \%$ & 9 & 15,25 & 59 & 100 \\
\hline Perempuan & 53 & $56 \%$ & 27 & $28,72 \%$ & 14 & 14,89 & 94 & 100 \\
\hline Total & 78 & & 52 & & 23 & & 153 & 100 \\
\hline
\end{tabular}

Financial Literacy Index Berdasarkan Usia

Tabel 4. Financial Literacy Index Berdasarkan Usia

\begin{tabular}{|c|c|c|c|c|c|c|c|c|}
\hline \multirow{2}{*}{ Usia } & \multicolumn{2}{|c|}{ Low } & \multicolumn{2}{|c|}{ Moderate } & \multicolumn{2}{|c|}{ High } & \multicolumn{2}{|c|}{ Total } \\
\hline & Jumlah & $\%$ & Jumlah & $\%$ & Jumlah & $\%$ & Jumlah & $\%$ \\
\hline \multicolumn{9}{|l|}{ FLI_BFL } \\
\hline$<30$ thn & 6 & 31,58 & 5 & 26,32 & 8 & 42,10 & 19 & 100 \\
\hline $30-40$ thn & 18 & 32,14 & 17 & 30,36 & 21 & 37,50 & 56 & 100 \\
\hline $40-50$ thn & 15 & 33,33 & 15 & 33,33 & 15 & 33,33 & 45 & 100 \\
\hline$>50$ thn & 7 & 21,21 & 10 & 30,30 & 16 & 48,48 & 33 & 100 \\
\hline Total & 46 & & 47 & & 60 & & 153 & \\
\hline \multicolumn{9}{|l|}{ FLI_AFL } \\
\hline$<30$ thn & 14 & 73,68 & 5 & 26,32 & 0 & 0 & 19 & 100 \\
\hline $30-40$ thn & 43 & 76,79 & 11 & 19,64 & 2 & 3,57 & 56 & 100 \\
\hline $40-50$ thn & 34 & 75,56 & 8 & 17,78 & 3 & 6,67 & 45 & 100 \\
\hline$>50$ thn & 19 & 57,58 & 11 & 33,33 & 3 & 9,09 & 33 & 100 \\
\hline Total & 110 & & 35 & & 8 & & 153 & \\
\hline \multicolumn{9}{|l|}{ FLI_All } \\
\hline$<30$ thn & 10 & 52,63 & 6 & 31,58 & 3 & 15,79 & 19 & 100 \\
\hline $30-40$ thn & 29 & 51,79 & 22 & 39,29 & 5 & 8,93 & 56 & 100 \\
\hline $40-50$ thn & 25 & 55,56 & 13 & 28,89 & 7 & 15,56 & 45 & 100 \\
\hline$>50$ thn & 14 & 42,42 & 11 & 33,33 & 8 & 24,24 & 33 & 100 \\
\hline Total & & & & & & & & \\
\hline
\end{tabular}

Sumber: data primer diolah

Tampilan tabel 4 menunjukkan Basic 26,32\% dan yang tergolong rendah 31,58\%. Financial Literacy (BFL) yang usianya Usia 30-40 tahun BFL yang kategori rendah dibawah 30 tahun masuk kategori tinggi sebesar 32,14\%, moderat 30,36\%, dan sebesar $42,10 \%$, yang tergolong moderat kategori tinggi sebesar 37,50\%. BFL untuk 
usia 40-50 tahun seimbang besarnya yakni $33,33 \%$ untuk kategori rendah, moderat dan tinggi. Sedangkan BFL yang usaianya diatas 50 tahun dominan pada kategori tinggi $(48,48 \%)$, moderat sebesar $30,30 \%$ dan rendah sebesar 21,21\%. Advanced Financial Literacy (AFL) kategori rendah dominan pada semua golongan usia, untuk yang dibawah 30 tahun jumlah responden yang AFL-nya rendah sebesar 73,68\%, untuk 30-40 tahun sebesar 76,79\%, kelompok usia 40-50 tahun $75,56 \%$, kelompok usia diatas 50 tahun sebesar 57,58\%. Untuk kategori moderat usia dibawah 30 tahun sebesar $26,32 \%$ usia 30 40 tahun sebesar $19,64 \%$, usia 40-50 tahun sebesar $17,78 \%$ dan diatas 50 tahun sebesar $33,33 \%$, sedangkan yang kategori AFL tinggi sangat sedikit jumlahnya (dibawah 10\%) di semua golongan usia, yang dibawah 30 tahun 0\%, 30-40 tahun 3,57\%, 40-50 tahun sebesar $6,67 \%$ dan diatas 50 tahun sebesar 9,09\%. Secara keseluruhan tingkat literasi keuangan untuk semua golongan usia dominan pada kategori rendah.

Hasil penelitian ini mengimplikasikan, perlunya upaya peningkatan pengetahuan keuangan dari kesadaran diri dosen sendiri, institusi/perguruan tinggi maupun pemerintah mengingat pengetahuan keuangan dosendosen di Palembang secara keseluruhan termasuk dalam kategori rendah. Dosen lakilaki sebagian besar masuk dalam kategori rendah dan moderat, sedangkan perempuan sebagian besar masuk dalam kategori rendah. Sehingga dosen laki-laki maupun perempuan perlu meningkatkan pengetahuan keuangannya terutama pada pengetahuan keuangan tingkat lanjutan. Sebagian besar dosen pada usia berapapun mereka, memiliki pengetahuan keuangan yang rendah. Dengan demikian upaya peningkatan pengetahuan keuangan dapat dilakukan tidak hanya untuk dosen perempuan tetapi juga laki-laki. Upaya Pengetahuan keuangan juga perlu dilakukan secara merata tanpa membedakan kelompok usia seseorang.

\section{SIMPULAN DAN SARAN}

Penelitian ini memberikan simpulan sebagai berikut: Secara keseluruhan Financial
Literacy Index atau tingkat literasi keuangan dosen-dosen di Palembang sebesar 57,46 termasuk kategori rendah dengan klasifikasi Basic Financial Literacy Index sebesar 68,45 termasuk dalam kategori moderat, dan Advanced Financial Literacy Index sebesar 46,47 termasuk dalam kategori rendah. Basic Financial Literacy Index untuk kategori moderat dan tinggi lebih dominan laki-laki dibandingkan perempuan, sebaliknya untuk kategori rendah perempuan lebih dominan dari laki-laki. Demikian juga untuk Advanced Financial Literacy Index laki-laki lebih dominan pada kategori moderat dan tinggi, sedangkan perempuan lebih dominan pada kategori rendah. Basic Financial Literacy Index berdasarkan golongan usia yang masuk dalam kategori tinggi dominan disetiap golongan usia sedangkan kategori rendah dan moderat cenderung memiliki proporsi yang seimbang.Sebaliknya untuk Advanced Financial Literacy Index dominan di kategori rendah mencapai diatas 70\%, kurang dari 10\% yang masuk kategori tinggi.

Penelitian ini hanya menggunakan simple weight dalam analisis datanya, penelitian lanjutan menggunakan alat analisis lain didalam menentukan indeks literasi keuangan. Penelitian ini hanya menganalisis berdasarkan gender dan usia, riset selanjutnya diharapkan dapat menganalisis tingkat literasi keuangan berdasarkan faktor lainnya seperti tingkat pendidikan, penghasilan per bulan, dan lainnya. Penelitian ini belum difokuskan untuk melihat keterkaitan antara tingkat literasi keuangan dengan kepemilikan produk keuangan, kedepan analisis dapat diperdalam dengan melihat keterkaitan antara tingkat pendapatan dengan kepemilikan produk keuangan.

\section{ACKNOWLEDGEMENT}

Penelitian ini dapat diselesaikan tidak terlepas dari bantuan dari Universitas Katolik Musi Charitas (UKMC). Oleh karenanya, kami mengucapkan terima kasih kepada UKMC yang telah mensupport kegiatan penelitian ini berupa fasilitas dan pendanaan. 


\section{DAFTAR PUSTAKA}

ANZ. 2015. Survey of Adult financial literacy in Australia. Full report of the results from the 2014 ANZ survey.

Aribawa, Dwitya. 2016. Pengaruh Literasi Keuangan Terhadap Kinerja Dan Keberlangsungan UMKM Di Jawa Tengah,Siasat Bisnis, Vol. 20 (1),hal. 1-13

Atkitson, A, McKay, S, Kempson, E \& Collard, S. 2006. Levels of Financial Capability in the $U K$, Result of a baseline Survey: Financial Service Authority

Beal, D.J \& Delpachtra, S.B. 2003. Financial Literacy Among Australian Universty Students. Economic Papers, 22, pp. 65-78.

Byrne, A. 2007. Employee Saving and Investment Decisions in Defined Contribution Pension Plans: Survey Evidence From the U.K.Financial Services Review, Vol 16.

Chen, H., \& Volpe, R.P. 1998. An Analysis of Personal Financial Literacy Among College Student. Financial Services Review, Vol. 7(2), pp. 107-128.

Chen, H., \& Volpe, R.P. 2002. Gender Differences in Personal Financial Literacy Among College Students. Financial Services Review, 11 (3): 289-307.

Definit, OJK,dan USAID. 2013. Developing Indonesian Financial Literacy Index. Jakarta. USAID.

Hira, Tahira, and Cazilia Loibl. 2005. Understanding the Impact of Employer-Provided Financial Education on Workplace Satisfaction. Journal of Consumer Affairs, 39 (Summer): 173194.

Hung, Angela. A, Andrew M. Parker, Joanne K.Yoong. 2009. Defining and Measuring Financial Literacy SSRN Electronic Journal. https://www.researchgate.net/publication/46464346_ Defining_and_Measuring_Financial_Literacy

Huston, Sandra J. 2010. Measuring Financial Literacy. The Journal of Consumer Affairs, Vol $44(2)$

Ibrahim, D., Rabitah Harun \& Zuraidah Mohamed Isa. 2009. A Study on Financial Literacy of Malaysian Degree Students. Cross-cultural Communication ISSN 1712-8358, Vol. 5, No. 4, $2009: 51-59$

Ika Aprillia. 2017. Memahami Consumer Behaviour Sebagai Kunci Menuju Literasi Keuangan Kompas.com http://ekonomi.kompas.com/read/2017/05/04/095403726/ memahami. consumer.behaviour.sebagai.kunci.menuju.literasi.keuangan diunduh 1 Agustus 2017

Indrawati,Yulia. 2015. Determinan Dan Strategi Peningfkatan Literasi Keuangan Masyarakat Perkotaan DI Kabupaten Jember. Ringkasan EksekutifPenelitian Dosen Pemula, Lembaga Penelitian Universitas Jember. http://repository.unej.ac.id/handle/123456789/63430. Diunduh 1 Agustus 2017

Keown, L.A. 2011. The financial knowledge of Canadians. Canadian SocialTrends, 11(008), pp. 30-39.

Krishna, A., Rofaida, R., \& Sari, M. 2010. Analisis tingkat literasi keuangan di kalangan mahasiswa dan faktor-faktor yang mempengaruhinya. Proceedings of the 4thInternational Conference on Teacher Education; Join Conference UPI \& UPSI Bandung, Indonesia

Lusardi, A., and O. Mitchell, 2014. The Economic Importance of Financial Literacy: Theory 
and Evidence. Journal of Economic Literature, Vol. 52(1), pp. 5-44

Margaretha, Farah\& Reza Arief Prambudhi. 2015. Tingkat Literasi Keuangan Pada Mahasiswa S-1 Fakultas Ekonomi.JMK, Vol 17 (1), hal 76-85

Mendari, Anastasia Sri\& Kewal, Suramaya Suci. 2013. Tingkat Literasi Keuangan Di Kalangan Mahasiswa STIE Musi,Jurnal Economia, Vol. 9 (2), Oktober 2013

Nababan, D.,\& Sadalia, I. 2013. Analisis personal financial literacy dan financial behavior mahasiswa strata I fakultas ekonomi Universitas Sumatera Utara., dari https://jurnal.usu. ac.id/index.php/jmim/article/view/651.Diunduh 1 Agustus 2017

Nidar, S. R.,\& Bestari, S. 2012. Personal literacy among university students(case study at Padjajaran University students, Bandung, Indo-nesia. World Journal of Social Sciences, Vol. 2(4), pp.162-171.

Otoritas Jasa keuangan. 2013. Strategi Nasional Literasi Keuangan Indonesia, Jakarta. www. ojk.go.id

Otoritas Jasa Keuangan. 2016. Survei Literasi Keuangan dan Inklusi, Jakarta. www.ojk.go.id

OECD INFE, 2012. Financial Literacy Assessment Framework. http://www.oecd.org/pisa/ pisaproducts/ 46962580.pdf diunduh 31 Juli 2017

Riadi, Edi. 2016. Statistika Penelitian (Analisis Manual dan IBM SPSS). Penerbit Andi Offset. Yogyakarta.

Rita,Maria, Rio \& Benny Santoso. 2015. Literasi Keuangan Dan Perencanaan Keuangan Pada Dana Pendidikan Anak. Jurnal Ekonomi, Vol.20 (2),hal. 212-227.

Sekaran, Uma. 2009. Research Methods For Business. Metodologi Penelitian untuk Bisnis. Penerbit Salemba Empat. Jakarta.

Sugiarto Agus. 2013. Literasi Keuangan Untuk Memakmurkan Rakyat. Majalah Edukasi Konsumen, Agustus 2013. https://sikapiuangmu.ojk.go.id/FrontEnd/CMS/ DetailMateri/5 diunduh 31 Juli 2017

Taft, M. K., Hosein, Z. Z., \& Mehrizi, S. M.T. 2013. The relation between financial literacy, financial wellbeing and financial concerns. International Journal of Business and Management, Vol. 8(11), pp. 63-75

Van Rooij, M., Lusardi, A., \& Alesssie, R. 2007. Financial Literacy and Stock Market Participation. MRRC Working Paper 2007-162.

Volpe, Ronald P., Joseph E. Kotel, and Haiyang Chen. 2002. A Survey of Investment Literacy among Online Investors. Financial Counseling and Planning, 13 (1): 1-13.

Yunastuti, Rina Milyati, Vitratin, dan Novita Sari. 2015. The Influence of Sevice Quality On Students Satisfaction At Private Universities In Bandar Lampung. Proceeding International Conference On Information Technology And Business. ISSN 2460-7223.https://www.google.co.id/url?sa=t\&rct=j\&q=\&esrc=s\&source=web\&c$\mathrm{d}=1 \& \mathrm{cad}=\mathrm{rja} \&$ uact $=8 \&$ ved $=0$ ahUKEwis4b6q1 rPWAhUgTo8KHYE7BXgQFggmMAA\&url=https $\% 3 \mathrm{~A} \% 2 \mathrm{~F} \% 2 \mathrm{Fjurnal}$. darmajaya.ac.id\%2Findex.php $\% 2$ Ficitb $\% 2$ Farticle\%2Fdownload\%2F449\%2F285\&usg=AFQjCNGZ7xaeWUK-ID2lqtbbjbrAGs5K-w 